\title{
Association between acquired resistance to PLX4032 (vemurafenib) and ATP-binding cassette transporter expression
}

\author{
Martin Michaelis ${ }^{1,2,6}$, Florian Rothweiler ${ }^{1}$, Thomas Nerreter ${ }^{1}$, Marijke van Rikxoort ${ }^{1,7}$, Richard Zehner ${ }^{3}$, \\ Wilhelm G Dirks ${ }^{4}$, Michael Wiese ${ }^{5}$ and Jindrich Cinatl $\mathrm{Jr}^{1 *}$
}

\begin{abstract}
Background: Various kinase inhibitors are known to be ATP-binding cassette (ABC) transporter substrates and resistance acquisition to kinase inhibitors has been associated to increased $A B C$ transporter expression. Here, we investigated the role of the $A B C$ transporters $A B C B 1, A B C C 1$, and $A B C G 2$ during melanoma cell resistance acquisition to the V600-mutant BRAF inhibitors PLX4032 (vemurafenib) and PLX4720. PLX4032 had previously been shown to interfere with $A B C B 1$ and $A B C G 2$. PLX4720 had been demonstrated to interact with ABCB1 but to a lower extent than PLX4032.

Findings: PLX4032 and PLX4720 affected ABCC1- and ABCG2-mediated drug transport in a similar fashion. In a panel of 16 V600E BRAF-mutated melanoma cell lines consisting of four parental cell lines and their sub-lines with acquired resistance to PLX4032, PLX4720, vincristine (cytotoxic $A B C B 1$ and $A B C C 1$ substrate), or mitoxantrone (cytotoxic ABCG2 substrate), we detected enhanced $A B C$ transporter expression in 4/4 cytotoxic $A B C$ transporter substrate-resistant, 3/4 PLX4720-resistant, and 1/4 PLX4032-resistant melanoma cell lines.

Conclusion: PLX4032 has the potential to induce $A B C$ transporter expression but this potential is lower than that of PLX4720 or cytotoxic $A B C$ transporter substrates. Since $A B C$ transporters confer multi-drug resistance, this is of relevance for the design of next-line therapies.
\end{abstract}

Keywords: Vemurafenib, PLX4032, PLX4720, Acquired drug resistance, Melanoma, Mitoxantrone, Vincristine, ABCB1, $A B C C 1, A B C G 2$

\section{Findings}

The oncogenic V600-mutant BRAF inhibitor PLX4032 (vemurafenib) caused improved response and survival rates in V600-mutant BRAF melanoma patients but PLX4032 resistance formation remains inevitable. Resistance mechanisms involve activation of alternative kinases and non-related compensatory pathways $[1,2]$. Although protein kinase inhibitors are rather specific drugs (particularly in comparison to the cytotoxic anti-cancer chemotherapeutics) they are also known to exert off-target effects [3-5]. For example, different protein kinase inhibitors interfere with drug transport mediated by various ATP binding cassette $(\mathrm{ABC})$ transporters including

\footnotetext{
* Correspondence: Cinatl@em.uni-frankfurt.de

${ }^{1}$ Institut für Medizinische Virologie, Klinikum der Goethe-Universität, Paul Ehrlich-Str. 40, Frankfurt am Main 60596, Germany

Full list of author information is available at the end of the article
}

$\mathrm{ABCB} 1$ (also known as MDR1 or P-glycoprotein), ABCC1 (also known as MRP1), and ABCG2 (also known as BCRP) [3,4,6-9].

$\mathrm{ABC}$ transporters play important roles in the passage of drugs, xenobiotics, and food constituents through cellular and tissue barriers and consequently in their absorption, distribution, and excretion. Moreover, different $\mathrm{ABC}$ transporters are frequently found highly expressed on cancer cells playing an important role in cancer cell chemoresistance [10-12]. Resistance acquisition to kinase inhibitors may be associated with enhanced $A B C$ transporter expression on cancer cells [13-15].

Some information is already available on the effects of PLX4032 and the closely related V600-mutant BRAF inhibitor PLX4720 [16] on ABC transporter function. PLX4032 and PLX4720 both interfere with ABCB1mediated drug transport [17-19]. PLX4032 was also shown 
to interact with ABCG2 (also known as BCRP) $[17,18]$. ABCG2 expression was suggested to be an acquired resistance mechanism to PLX4032 [20] although data on ABCG2 expression in cells with acquired PLX4032 resistance are missing.

Recently, we had shown that PLX4032 and PLX4720 differed in their effects on ABCB1-mediated drug transport. Despite the structural similarity of these compounds PLX4032 interfered stronger with ABCB1 function than PLX4720 [19]. Here, we 1) compared the effects of PLX4032 and PLX4720 on ABCG2 and ABCC1 and 2) investigated whether resistance acquisition to these compounds may be associated with enhanced ABC transporter expression.

\section{Effects of PLX4032 and PLX4720 on ABCG2 and ABCC1 function}

To study the effects of PLX4032 and PLX4720 on ABCG2, an ABCG2-expressing sub-line of the BRAF wild-type neuroblastoma cell line UKF-NB-3 (UKF-NB-3 ${ }^{\text {ABCG2 }}$ ) was used that had been established by lentiviral transduction with LeGO vectors (www.lentigo-vectors.de) as described previously [21,22]. All experimental procedures were performed as described previously [22]. PLX4032 and PLX4720 treatment of UKF-NB-3 ${ }^{\text {ABCG2 }}$ cells (but not of UKF-NB-3 cells or UKF-NB-3 cells transduced with a control vector) resulted in a similar dose-dependent increase in the cellular accumulation of the fluorescent ABCG2 substrate BODIPY-prazosine (Figure 1A) without affecting ABCG2 expression (Additional file 1: Figure S1).

In wash-out experiments, cellular BODIPY-prazosine fluorescence levels declined rapidly in UKF-NB-3 ${ }^{\mathrm{ABCG} 2}$ cells (Figure 1B), likely because the removal of extracellular PLX4032 and PLX4720 resulted in the rapid ABCG2-mediated efflux of PLX4032/PLX4720 and BODIPY-prazosine. PLX4032 and PLX4720 increased ABCG2 ATPase activity in an isolated membrane assay (Figure $1 \mathrm{C}$ ) indicating binding and activation of ABCG2 by these compounds. Further, PLX4032 and PLX4720 concentration-dependently enhanced the toxicity of the
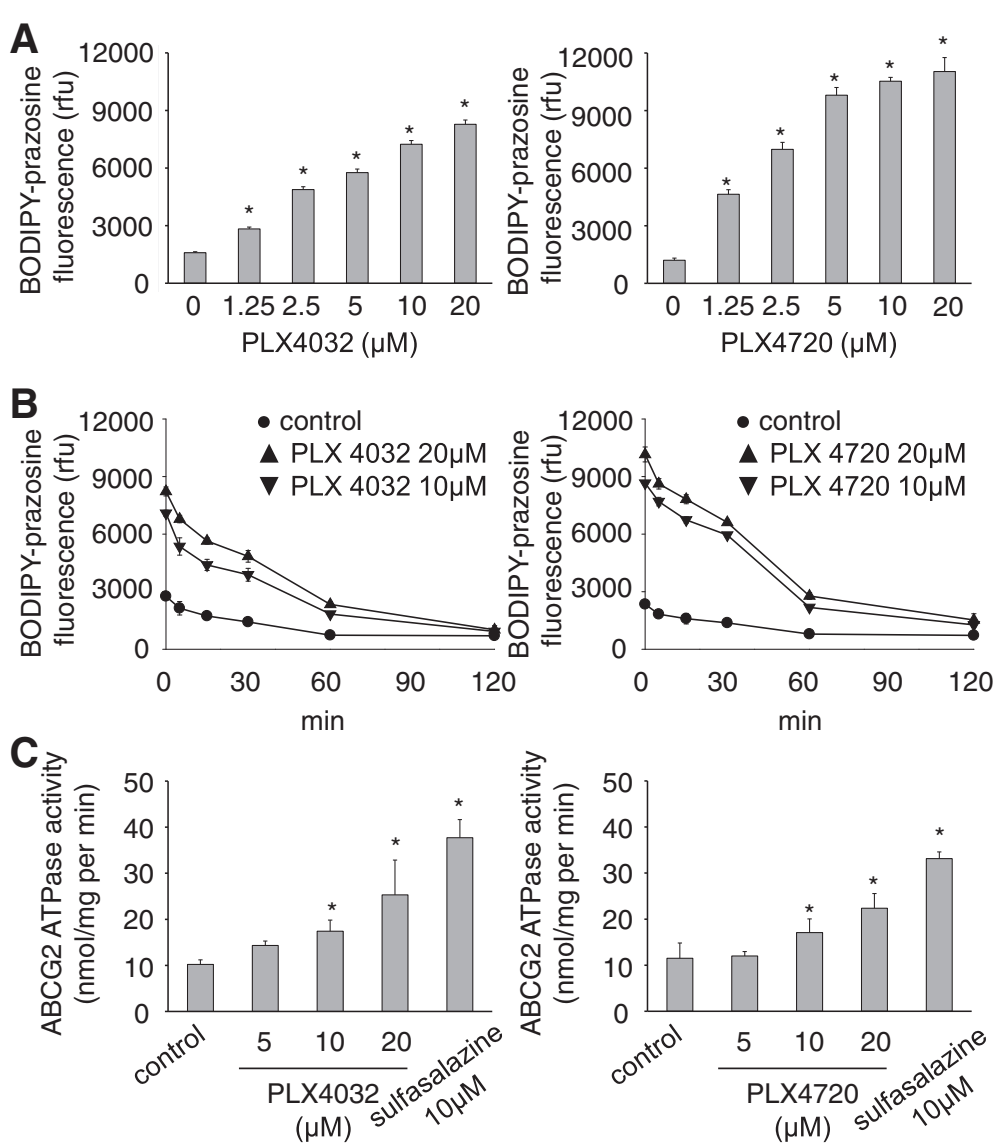

Figure 1 Effect of PLX4032 and PLX4720 on ABCG2 activity. A) Influence of PLX4032 or PLX4720 on BODIPY-prazosine (1 $\mu$ M) fluorescence in UKF-NB-3 $3^{A B C G 2}$ cells, B) time kinetics of BODIPY-prazosine (1 $\mu$ M) fluorescence in UKF-NB-3 ${ }^{A B C G 2}$ cells in the presence of PLX4032 or PLX4720 after a 60 min pre-incubation period with subsequent wash-out of extracellular BODIPY-prazosine and PLX4032 or PLX4720 (control = BODIPY-prazosine incubation in the absence of drugs). C) ABCG2 ATPase activity in isolated membranes in the presence of PLX4032 or PLX4720 (control=activity in the absence of drugs). Sulfasalazine, a known ABCG2 substrate, was used for comparison. ${ }^{*} \mathrm{P}<0.05$ relative to non-treated controls. 
ABCG2 substrate mitoxantrone in UKF-NB-3 ${ }^{\text {ABCG2 }}$ cells but not of non-transduced UKF-NB-3 cells or UKF-NB-3 cells transduced with a control vector (Additional file 2: Table S1) as indicated by MTT assay after five day incubation. These findings are in accordance with previous studies demonstrating PLX4032 to be an ABCG2 substrate $[17,18,20]$.

The effects of PLX4032 and PLX4720 on ABCC1 were investigated in the $\mathrm{ABCC} 1$-expressing cell lines $\mathrm{G} 62$ (glioblastoma) and $\mathrm{PC}^{\mathrm{r}} \mathrm{VCR}^{20}$ (prostate cancer) [22]. PLX4032 and PLX4720 similarly increased the accumulation of the fluorescent ABCC1 substrate 5-CFDA in G62 cells in a concentration-dependent manner (Figure 2A) without affecting ABCC1 expression (Additional file 1: Figure S1). 5-CFDA fluorescence declined rapidly after wash-out of PLX4032 or PLX4720 (Figure 2B). Both substances increased ABCC1 ATPase activity in an isolated membrane assay (Figure $2 \mathrm{C}$ ) and the toxicity of the $\mathrm{ABCC} 1$ substrate vincristine in $\mathrm{G} 62$ and $\mathrm{PC} 3{ }^{\mathrm{r}} \mathrm{VCR}^{20}$ cells
(Additional file 3: Table S2) in a concentration-dependent manner. These findings appear to contrast other findings that suggested PLX4032 not to be an ABCC1 substrate [20]. The differences may be explained by the use of different $\mathrm{ABCC} 1$ substrates and different cellular models. Depending on the exact mode or strength of interaction of $\mathrm{ABC}$ transporter modulators with an $\mathrm{ABC}$ transporter, different substrates may not always compete for the same binding site. For example, activators of ABCB1 activity that enhance the efflux of certain $A B C B 1$ substrates were described [23]. Moreover, certain ABCB1 modulators were shown to exert differing effects on the cellular accumulation of distinct ABCB1 substrates [24].

PLX4032 and PLX4720 also sensitised two wildtype BRAF melanoma cell lines, IPC-298 and SK-Mel-30 (DSMZ, Braunschweig, Germany), that express ABCB1, ABCC1, and ABCG2 (Additional file 4: Table S3) to vincristine and mitoxantrone (Additional file 5: Table S4). Taken together, these results show that PLX4032 and
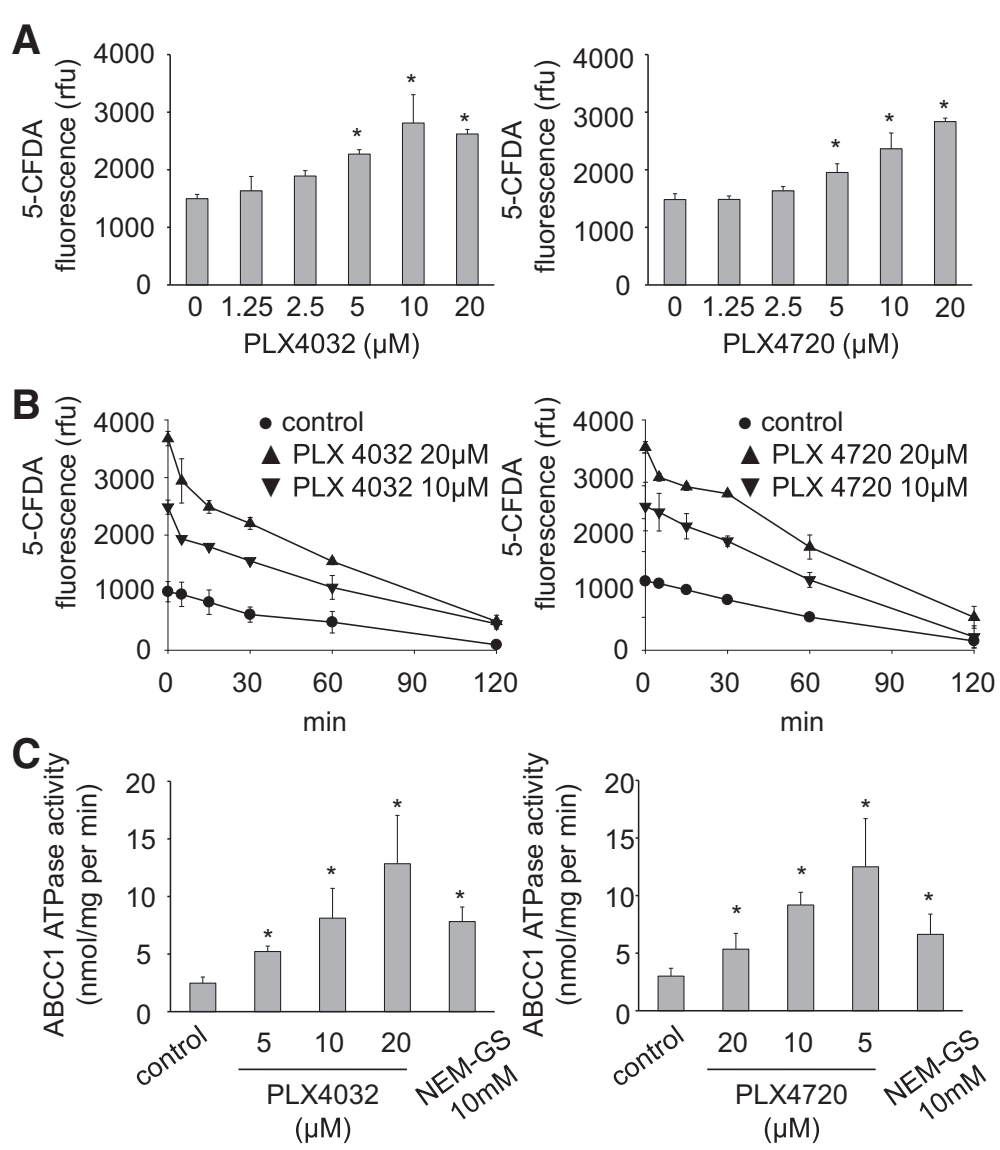

Figure 2 Effect of PLX4032 and PLX4720 on ABCC1 activity. A) Influence of PLX4032 or PLX4720 on 5-CFDA (1 $\mu$ M) fluorescence in G62 cells, B) time kinetics of 5-CFDA (1 $\mu \mathrm{M})$ fluorescence in G62 cells in the presence of PLX4032 or PLX4720 after a 60 min pre-incubation period with subsequent wash-out of extracellular 5-CFDA and PLX4032 or PLX4720 (control=5-CFDA incubation in the absence of drugs). C) ABCC1 ATPase activity in isolated membranes in the presence of PLX4032 or PLX4720 (control = activity in the absence of drugs). NEM-GS, a known ABCC1 substrate, was used for comparison. ${ }^{*} \mathrm{P}<0.05$ relative to non-treated controls. 
PLX4720 interfere with ABCC1 and ABCG2 in a similar fashion.

\section{ABC transporter expression in V600E BRAF-mutated} melanoma cell lines with acquired resistance to PLX4032 and PLX4720

Next, we investigated the expression of $\mathrm{ABCB} 1, \mathrm{ABCC} 1$, and ABCG2 in the V600E BRAF-mutated melanoma cell lines Colo-679, IGR-39, MelHO, and RVH-421 (DSMZ, Braunschweig, Germany) and their sub-lines with acquired resistance to PLX4032 (Colo-679 ${ }^{\mathrm{r} L X} 4032^{10 \mu \mathrm{M}}$,
MelHO ${ }^{\mathrm{r}} \mathrm{PLX} 4032^{10 \mu \mathrm{M}}$, IGR-39 ${ }^{\mathrm{r}} \mathrm{PLX} 4032^{20} \mu \mathrm{M}, \mathrm{RVH}-$ $421^{\mathrm{r}} \mathrm{PLX} 4032^{10 \mu \mathrm{M}}$ ), PLX4720 (Colo-679 ${ }^{\mathrm{r}} \mathrm{PLX} 4720^{10 \mu \mathrm{M}}$, MelHO ${ }^{\mathrm{r}} \mathrm{PLX} 4720^{10 \mu \mathrm{M}}$, IGR-39 ${ }^{\mathrm{r}} \mathrm{PLX} 4720^{20 \mu \mathrm{M}}, \mathrm{RVH}-421^{\mathrm{r}}$ PLX4720 $\left.{ }^{10} \mu \mathrm{M}\right)$, vincristine (Colo- $679^{\mathrm{r}} \mathrm{VCR}^{20}$, IGR-39 ${ }^{\mathrm{r}}$ $\left.\mathrm{VCR}^{10}, \mathrm{MelHO}^{\mathrm{r}} \mathrm{VCR}^{20}\right)$, or mitoxantrone $\left(\mathrm{RVH}-421^{\mathrm{r}}\right.$ Mitox $^{10}$ ) (Figure 3; Additional file 6: Table S5) that were derived from the Resistant Cancer Cell Line (RCCL) collection (www.kent.ac.uk/stms/cmp/RCCL/RCCLabout.html). Treatment of melanoma cells with PLX4032 or cytotoxic anti-cancer drugs had been shown to result in the selection of ABCB5-expressing cells [25]. However, we did not
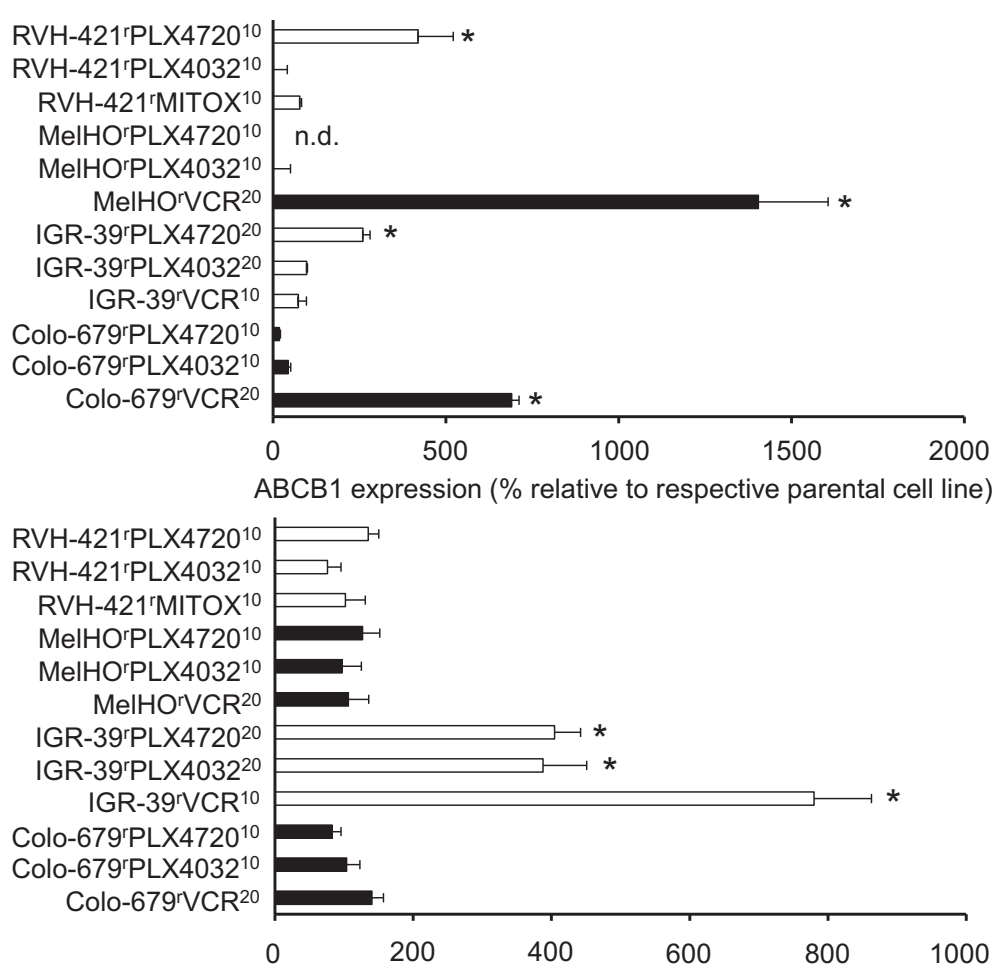

$\mathrm{ABCC} 1$ expression (\% relative to respective parental cell line)

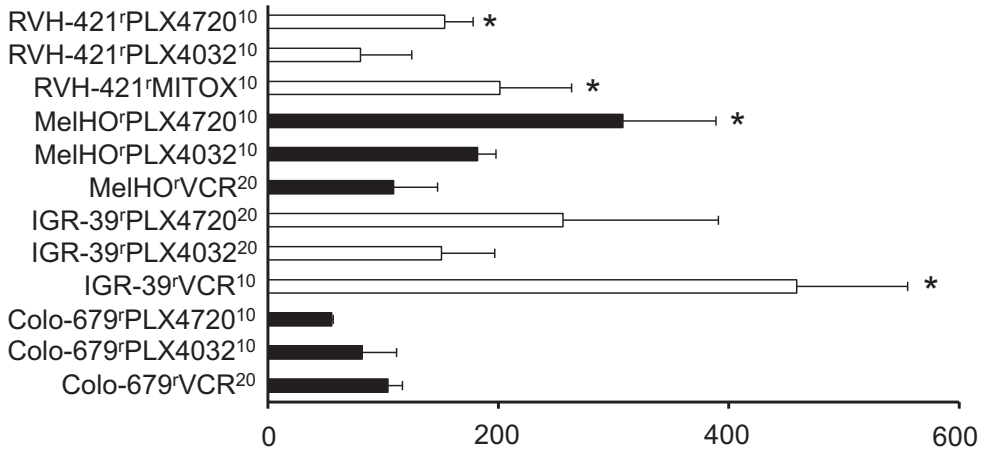

ABCG2 expression (\% relative to respective parental cell line)

Figure 3 Expression of $A B C B 1, A B C C 1$, and ABCG2 in V600 BRAF-mutated melanoma cells adapted to PLX4032, PLX4720, or the cytotoxic $A B C$ transporter substrates vincristine (VCR) or mitoxantrone (MITOX) relative to the respective parental cell lines. White and black bars are used to facilitate the identification of resistant sub-lines that are derived from the same parental cell line. *P $<0.05$ relative to parental cells. 
detect enhanced ABCB5 expression in our resistance models relative to the parental sensitive cells.

Colo- $679^{\mathrm{r}} \mathrm{VCR}^{10}, \mathrm{MelHO}^{\mathrm{r}} \mathrm{VCR}^{20}$, IGR-39 $\mathrm{PLX} 4720^{20 \mu \mathrm{M}}$, and RVH-421 ${ }^{\mathrm{r}}$ PLX4720 $0^{10 \mu \mathrm{M}}$ expressed increased ABCB1 levels, IGR-39 $9^{\mathrm{r}} \mathrm{VCR}^{10}$, IGR-39 ${ }^{\mathrm{r}} \mathrm{PLX} 4032^{20 \mu \mathrm{M}}$, and IGR-39 PLX4720 $20 \mu \mathrm{M}$ high ABCC1 levels, IGR-39 ${ }^{\mathrm{r}} \mathrm{VCR}^{10}, \mathrm{MelHO}^{\mathrm{r}}$ PLX4720 $0^{10 \mu \mathrm{M}}$, RVH-421 ${ }^{\mathrm{r}} \mathrm{MITOX}^{10}$, and RVH-421 ${ }^{\mathrm{r}}$ PLX $4720^{10 \mu \mathrm{M}}$ high ABCG2 levels (Figure 3). The ABC transporters conferred resistance to the cytotoxic $A B C$ transporter substrates vincristine $(\mathrm{ABCB} 1, \mathrm{ABCC} 1)$ and mitoxantrone (ABCG2) but not to PLX4032 or PLX4720 (Additional file 7: Table S6). These data show that V600mutant melanoma cells with acquired resistance to PLX4032 may express enhanced ABC transporter levels. However, the potential of PLX4032 to induce ABC transporter expression appears to be lower compared to PLX4720, although both molecules differ in just one phenyl group (Additional file 8: Figure S2), and cytotoxic $\mathrm{ABC}$ transporter substrates.

\section{Discussion}

The finding that resistance acquisition to PLX4032 and PLX4720 may be associated with enhanced ABCB1 expression is in line with data showing resistance acquisition to other kinase inhibitors to be associated with ABCB1, ABCC1, and ABCG2 expression [13-15,26].

PLX4032 had previously been shown to interfere substantially stronger with ABCB1 than PLX4720 [19] while we show here that both compounds display similar effects on ABCG2 and ABCC1. Therefore, differing levels of interaction with the investigated $\mathrm{ABC}$ transporters do not explain the enhanced $\mathrm{ABC}$ transporter expression in PLX4720-resistant relative to PLX4032-resistant cells. $\mathrm{ABC}$ transporter up-regulation may be part of the cellular stress response, and anti-cancer drug-induced stress may induce $A B C$ transporter expression regardless of whether the drugs are $A B C$ transporter substrates [27-29]. PLX4720 induced more pronounced toxic off-target effects $\left(\mathrm{IC}_{50} 15.04 \pm 0.60 \mu \mathrm{M}\right.$ in BRAF wild-type UKF-NB-3 cells) than PLX4032 ( $\mathrm{IC}_{50} 30.61 \pm 1.37 \mu \mathrm{M}$ in UKF-NB-3). Also, we detected enhanced ABCG2 expression in IGR- $39^{\mathrm{r}} \mathrm{VCR}^{10}$ cells although vincristine is not regarded to be an ABCG2 substrate.

In conclusion, we show that PLX4032 and PLX4720 interfere with $\mathrm{ABCC} 1$ - and $\mathrm{ABCG} 2$-mediated drug transport. Since $A B C$ transporters play important roles in the absorption, distribution, and excretion of drugs these findings are of potential clinical relevance when PLX4032 is co-administered with anti-cancer drugs or non-cancerrelated drugs that are $A B C$ transporter substrates [10-12]. The investigation of a panel of 16 BRAF V600-mutant melanoma cell lines suggested that resistance acquisition to PLX4032 may be associated with enhanced ABC transporter expression although PLX4720 and cytotoxic ABC transporter substrates are stronger inducers of $\mathrm{ABC}$ transporter expression than PLX4032. This is of relevance for the design of next-line therapies for melanomas with acquired PLX4032 resistance since $\mathrm{ABC}$ transporters including $\mathrm{ABCB} 1, \mathrm{ABCC} 1$, and $\mathrm{ABCG} 2$ confer multi-drug resistance [10-12]. The potential clinical implications of our findings are outlined in Additional file 9: Figure S3.

\section{Availability of supporting data}

The data sets supporting the results of this article are included within the article and its additional files.

\section{Additional files}

Additional file 1: Figure S1. Effects of $P L X 4032$ and $P L X 4720$ on $A B C G 2$ and $A B C C 1$ expression. A) ABCG2 expression in UKF-NB-3ABCG2 cells after treatment with PLX4032 or PLX4720 for different incubation periods in \% relative to non-treated control as determined by flow cytometry; B) ABCC1 expression in G62 cells after treatment with $\mathrm{PLX} 4032$ or $\mathrm{PLX} 4720$ for different incubation periods in \% relative to non-treated control as determined by flow cytometry.

Additional file 2: Table S1. A. Influence of PLX4032, PLX4720, or the ABCG2 inhibitor fumitremorgin $C$ on the concentration of the ABCG2 substrate mitoxantrone that decreases the viability of $A B C G 2$-expressing UKF-NB-3 ${ }^{A B C G 2}$ cells by 50\% (IC50). B. Influence of PLX4032 or the ABCG2 inhibitor fumitremorgin $C$ on the concentration of the $A B C G 2$ substrate mitoxantrone that decreases the viability of UKF-NB-3 cells by $50 \%$ (IC50). C. Influence of PLX4720 or the ABCG2 inhibitor fumitremorgin C on the concentration of the $A B C G 2$ substrate mitoxantrone that decreases the viability of UKF-NB-3 cells by $50 \%$ (IC50). D. Influence of PLX4032 or the $A B C G 2$ inhibitor fumitremorgin $C$ on the concentration of the $A B C G 2$ substrate mitoxantrone that decreases the viability of UKF-NB-3 cells transduced with an empty control vector (as comparison to UKF-NB$3 A B C G 2)$ by $50 \%$ (IC50). E. Influence of PLX4720 or the ABCG2 inhibitor fumitremorgin $C$ on the concentration of the $A B C G 2$ substrate mitoxantrone that decreases the viability of UKF-NB-3 cells transduced with an empty control vector (as comparison to UKF-NB-3ABCG2) by 50\% (IC50).

Additional file 3: Table S2. A. Influence of PLX4032, PLX4720, or the ABCC1 inhibitor MK571 on the concentration of the ABCC1 substrate vincristine that decreases the viability of $A B C C 1$-expressing $\mathrm{G} 62$ cells by $50 \%$ (IC50). B. Influence of PLX4032 or the ABCC1 inhibitor MK571 on the concentration of the $A B C C 1$ substrate vincristine that decreases the viability of ABCC1-expressing PC3rVCR20 cells by 50\% (IC50). C. Influence of PLX4720 or the ABCC1 inhibitor MK571 on the concentration of the $A B C C 1$ substrate vincristine that decreases the viability of $A B C C 1$ expressing PC3rVCR20 cells by 50\% (IC50)

Additional file 4: Table S3. A. ABCB1 expression in melanoma cells and the influence of the ABCB1 inhibitor PGP4008 $(2.5 \mu \mathrm{M})$ on the concentration of the $A B C B 1$ substrate vincristine that decreases the viability of melanoma cells by $50 \%$ (IC50). B. ABCC 1 expression in melanoma cells and the influence of the ABCC1 inhibitor MK571 (10 $\mu \mathrm{M})$ on the concentration of the $A B C C 1$ substrate vincristine that decreases the viability of melanoma cells by 50\% (IC50). C. ABCG2 expression in melanoma cells and the influence of the ABCG2 inhibitor fumitremorgin $C(10 \mu \mathrm{M})$ on the concentration of the ABCG2 substrate mitoxantrone that decreases the viability of melanoma cells by $50 \%$ (IC50).

Additional file 5: Table S4. Influence of PLX4032 (20 $\mu \mathrm{M})$ or PLX4720 $(20 \mu \mathrm{M})$ on the vincristine (substrate of $\mathrm{ABCB} 1$ and $\mathrm{ABCC}$ ) or mitoxantrone (substrate of $A B C G 2$ ) concentrations that reduce the cell viability by $50 \%$ (IC50) in the BRAF wild-type melanoma cell lines IPC298 and SK-MEL-30 that both express $A B C B 1, A B C C 1$, and $A B C G 2$.

Additional file 6: Table S5. Drug concentrations that decrease the viability of V600E BRAFmutated melanoma cells by 50\% (IC50). 
Additional file 7: Table S6. A. Influence of the $A B C B 1$ inhibitor verapamil $(10 \mu \mathrm{M})$ on the sensitivity of ABCB1-expressing melanoma cells to PLX4720 or the cytotoxic ABCB1 substrate vincristine. Concentrations that reduce the cell viability by $50 \%$ (IC50) were determined after a five day incubation period by MTT assay. B. Influence of the ABCC1 inhibitor verapamil $(10 \mu \mathrm{M})$ on the sensitivity of $A B C C 1$-expressing melanoma cells to PLX4032, PLX4720, or the cytotoxic ABCC1 substrate vincristine. Concentrations that reduce the cell viability by $50 \%$ (IC50) were determined after a five day incubation period by MTT assay. C. Influence of $A B C G 2$ inhibitor fumitremorgin $C(2.5 \mu \mathrm{M})$ on the sensitivity of $A B C G 2-$ expressing melanoma cells to PLX4720 or the cytotoxic ABCG2 substrate mitoxantrone. Concentrations that reduce the cell viability by $50 \%$ (IC50) were determined after a five day incubation period by MTT assay.

Additional file 8: Figure S2. Chemical structures of PLX4032 and PLX4720.

Additional file 9: Figure S3. Potential clinical implications of the findings presented in this report. A) PLX4032 and PLX4720 interfere with $A B C B 1, A B C C 1$, and $A B C G 2$ function. Since these $A B C$ transporters are expressed at physiological barriers and control the absorption, body distribution, and excretion of their substrates, inhibition of these transporters may modify the pharmacokinetics of co-administered $A B C$ transporter substrates including anti-cancer drugs and drugs that are administered for alternative indications (e.g. antihypertensive drugs). In addition, PLX4032 and PLX4720 may sensitise ABC transporter-expressing cancer cells to co-administered anti-cancer drugs that are $A B C$ transporter substrates. B) Resistance formation to PLX4032 and PLX4720 may be associated with enhanced ABC transporter expression in cancer cells. This enhanced $A B C$ transporter expression will result in cross-resistance of the PLX4032- or PLX4720-resistant cells to anti-cancer drugs that are substrates of the respective $A B C$ transporters.

\section{Competing interests}

The authors declare that they have no competing interest.

\section{Authors' contributions}

MM and JCjr designed the study, performed experiments, analysed data, and drafted the manuscript. FR and TN determined effects of PLX4032 and PLX4720 on ABC transporter function. MvR established and characterised drug-resistant melanoma cells. RZ and WGD authenticated and characterised the investigated cell lines. MW analysed $A B C$ transporter data and provided WK-X-34. All authors read and approved the final manuscript.

\section{Acknowledgements}

The authors thank Kristoffer Riecken and Boris Fehse (Universitätsklinikum Hamburg-Eppendorf) for provision of and support with the LeGO vectors. The work was supported by the Hilfe für krebskranke Kinder Frankfurt e.V. (JCjr, MM), the Frankfurter Stiftung für krebskranke Kinder (JCjr, MM), the Royal Society (MM), and the Kent Cancer trust (MM).

\section{Author details}

'Institut für Medizinische Virologie, Klinikum der Goethe-Universität, Paul Ehrlich-Str. 40, Frankfurt am Main 60596, Germany. ${ }^{2}$ Centre for Molecular Processing and School of Biosciences, University of Kent, Canterbury Kent CT2 7NJ, UK. ${ }^{3}$ Institut für Rechtsmedizin, Klinikum der Goethe-Universität, Kennedyallee 104, Frankfurt am Main 60596, Germany. ${ }^{4}$ Leibniz-Institute Deutsche Sammlung für Mikroorganismen und Zellkulturen $\mathrm{GmbH}$, Inhoffenstraße 7B, Braunschweig 38124, Germany. ${ }^{5}$ Pharmaceutical Institute, University of Bonn, An der Immenburg 4, Bonn 53121, Germany. ${ }^{6}$ Current address: Centre for Molecular Processing and School of Biosciences, University of Kent, Canterbury Kent CT2 7NJ, UK. ${ }^{7}$ Current address: Institute of Pharmacology and Toxicology, Biomedical Center (BMZ), University of Bonn, Bonn 53127, Germany.

Received: 21 August 2014 Accepted: 2 October 2014

Published: 10 October 2014

\section{References}

1. Bollag G, Tsai J, Zhang J, Zhang C, Ibrahim P, Nolop K, Hirth P. Vemurafenib: the first drug approved for BRAF-mutant cancer. Nat Rev Drug Discov 2012, 11:873-886.
2. Bucheit $A D$, Davies MA: Emerging insights into resistance to BRAF inhibitors in melanoma. Biochem Pharmacol 2014, 87:381-389.

3. Hegedus C, Ozvegy-Laczka C, Szakács G, Sarkadi B: Interaction of ABC multidrug transporters with anticancer protein kinase inhibitors: substrates and/or inhibitors? Curr Cancer Drug Targets 2009, 9:252-262.

4. Van Erp NP, Gelderblom H, Guchelaar HJ: Clinical pharmacokinetics of tyrosine kinase inhibitors. Cancer Treat Rev 2009, 35:692-706.

5. Force T, Kolaja KL: Cardiotoxicity of kinase inhibitors: the prediction and translation of preclinical models to clinical outcomes. Nat Rev Drug Discov 2011, 10:111-126.

6. Hegedus T, Orfi L, Seprodi A, Váradi A, Sarkadi B, Kéri G: Interaction of tyrosine kinase inhibitors with the human multidrug transporter proteins, MDR1 and MRP1. Biochim Biophys Acta 2002, 1587:318-325.

7. Shi Z, Peng XX, Kim IW, Shukla S, Si QS, Robey RW, Bates SE, Shen T, Ashby CR Jr, Fu LW, Ambudkar SV, Chen ZS: Erlotinib (Tarceva, OSI-774) antagonizes ATP-binding cassette subfamily B member 1 and ATP-binding cassette subfamily $\mathrm{G}$ member 2-mediated drug resistance. Cancer Res 2007, 67:11012-11020.

8. Hegedüs C, Ozvegy-Laczka C, Apáti A, Magócsi M, Német K, Orfi L, Kéri G, Katona M, Takáts Z, Váradi A, Szakács G, Sarkadi B: Interaction of nilotinib, dasatinib and bosutinib with $A B C B 1$ and $A B C G 2$ : implications for altered anti-cancer effects and pharmacological properties. Br J Pharmacol 2009, 158:1153-1164.

9. Hegedüs C, Truta-Feles K, Antalffy G, Várady G, Német K, Ozvegy-Laczka C, Kéri G, Orfi L, Szakács G, Settleman J, Váradi A, Sarkadi B: Interaction of the EGFR inhibitors gefitinib, vandetanib, pelitinib and neratinib with the ABCG2 multidrug transporter: Implications for the emergence and reversal of cancer drug resistance. Biochem Pharmacol 2012, 84:260-267.

10. Silverton $L$, Dean $M$, Moitra $K$ : Variation and evolution of the $A B C$ transporter genes $A B C B 1, A B C C 1, A B C G 2, A B C G 5$ and $A B C G 8$ : implication for pharmacogenetics and disease. Drug Metabol Drug Interact 2011, 26:169-179.

11. Tamaki A, lerano C, Szakacs G, Robey RW, Bates SE: The controversial role of $A B C$ transporters in clinical oncology. Essays Biochem 2011, 50:209-232.

12. leiri l: Functional significance of genetic polymorphisms in Pglycoprotein (MDR1, ABCB1) and breast cancer resistance protein (BCRP, ABCG2). Drug Metab Pharmacokinet 2012, 27:85-105.

13. Burger $H$, Van Tol H, Brok M, Wiemer EA, De Bruijn EA, Guetens G, De Boeck G, Sparreboom A, Verweij J, Nooter K: Chronic imatinib mesylate exposure leads to reduced intracellular drug accumulation by induction of the ABCG2 (BCRP) and ABCB1 (MDR1) drug transport pumps. Cancer Biol Ther 2005, 4:747-752.

14. Balabanov S, Gontarewicz A, Keller G, Raddrizzani L, Braig M, Bosotti R, Moll J, Jost E, Barett C, Rohe I, Bokemeyer C, Holyoake TL, Brümmendorf TH: Abcg2 overexpression represents a novel mechanism for acquired resistance to the multi-kinase inhibitor Danusertib in BCR-ABL-positive cells in vitro. PLoS One 2011, 6:e19164.

15. Tang C, Schafranek L, Watkins DB, Parker WT, Moore S, Prime JA, White DL, Hughes TP: Tyrosine kinase inhibitor resistance in chronic myeloid leukemia cell lines: investigating resistance pathways. Leuk Lymphoma 2011, 52:2139-2147.

16. Tsai J, Lee JT, Wang W, Zhang J, Cho H, Mamo S, Bremer R, Gillette S, Kong J, Haass NK, Sproesser K, Li L, Smalley KS, Fong D, Zhu YL, Marimuthu A, Nguyen H, Lam B, Liu J, Cheung I, Rice J, Suzuki Y, Luu C, Settachatgul C, Shellooe R, Cantwell J, Kim SH, Schlessinger J, Zhang KY, West BL, et al: Discovery of a selective inhibitor of oncogenic B-Raf kinase with potent antimelanoma activity. Proc Natl Acad Sci U S A 2008, 105:3041-3046.

17. Durmus S, Sparidans RW, Wagenaar E, Beijnen $J H$, Schinkel AH: Oral availability and brain penetration of the B-RAFV600E inhibitor vemurafenib can be enhanced by the P-GLYCOprotein (ABCB1) and breast cancer resistance protein (ABCG2) inhibitor elacridar. Mol Pharm 2012, 9:3236-3245.

18. Mittapalli RK, Vaidhyanathan S, Sane R, Elmquist WF: Impact of P-glycoprotein $(A B C B 1)$ and Breast Cancer Resistance Protein (ABCG2) on the brain distribution of a novel B-RAF Inhibitor: Vemurafenib (PLX4032). J Pharmacol Exp Ther 2012, 342:33-40.

19. Michaelis M, Rothweiler F, Nerreter T, Van Rikxoort M, Sharifi M, Wiese M, Ghafourian T, Cinatl J Jr: Differential effects of the oncogenic BRAF Inhibitor PLX4032 (vemurafenib) and its progenitor PLX4720 on ABCB1 function. J Pharm Pharm Sci 2014, 17:154-168.

20. Wu CP, Sim HM, Huang YH, Liu YC, Hsiao SH, Cheng HW, Li YQ, Ambudkar SV, Hsu SC: Overexpression of ATP-binding cassette transporter ABCG2 as a 
potential mechanism of acquired resistance to vemurafenib in BRAF (V600E) mutant cancer cells. Biochem Pharmacol 2013, 85:325-334.

21. Weber K, Bartsch U, Stocking C, Fehse B: A multicolor panel of novel lentiviral "gene ontology" (LeGO) vectors for functional gene analysis. Mol Ther 2008, 16:698-706.

22. Michaelis M, Rothweiler F, Nerreter T, Sharifi M, Ghafourian T, Cinatl J Jr: Karanjin interferes with $\mathrm{ABCB} 1, \mathrm{ABCC} 1$, and $\mathrm{ABCG}$. J Pharm Pharm SCI 2014, 17:92-105.

23. Sterz K, Möllmann L, Jacobs A, Baumert D, Wiese M: Activators of P-glycoprotein: Structure-activity relationships and investigation of their mode of action. ChemMedChem 2009, 4:1897-1911.

24. Häcker HG, de la Haye A, Sterz K, Schnakenburg G, Wiese M, Gütschow M: Analogs of a 4-aminothieno[2,3-d]pyrimidine lead (QB13) as modulators of P-glycoprotein substrate specificity. Bioorg Med Chem Lett 2009, 19:6102-6105.

25. Chartrain M, Riond J, Stennevin A, Vandenberghe I, Gomes B, Lamant L, Meyer N, Gairin JE, Guilbaud N, Annereau JP: Melanoma chemotherapy leads to the selection of ABCB5-expressing cells. PLoS One 2012, 7:e36762.

26. Brózik A, Hegedüs C, Erdei Z, Hegedus T, Özvegy-Laczka C, Szakács G, Sarkadi B: Tyrosine kinase inhibitors as modulators of ATP binding cassette multidrug transporters: substrates, chemosensitizers or inducers of acquired multidrug resistance? Expert Opin Drug Metab Toxicol 2011, 7:623-642.

27. Chaudhary PM, Roninson IB: Induction of multidrug resistance in human cells by transient exposure to different chemotherapeutic drugs. J Nat/ Cancer Inst 1993, 85:632-639.

28. Sukhai $M$, Piquette-Miller $M$ : Regulation of the multidrug resistance genes by stress signals. J Pharm Pharm Sci 2000, 3:268-280.

29. Cressman AM, Petrovic V, Piquette-Miller M: Inflammation-mediated changes in drug transporter expression/activity: implications for therapeutic drug response. Expert Rev Clin Pharmacol 2012, 5:69-89

doi:10.1186/1756-0500-7-710

Cite this article as: Michaelis et al:: Association between acquired resistance to PLX4032 (vemurafenib) and ATP-binding cassette transporter expression. BMC Research Notes 2014 7:710.

\section{Submit your next manuscript to BioMed Central and take full advantage of:}

- Convenient online submission

- Thorough peer review

- No space constraints or color figure charges

- Immediate publication on acceptance

- Inclusion in PubMed, CAS, Scopus and Google Scholar

- Research which is freely available for redistribution 